DOI: https://doi.org/10.47405/mjssh.v6i1.609

\begin{tabular}{|c|c|}
\hline 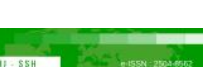 & Malaysian Journal of Social Sciences and Humanities (MJSSH) \\
\hline Malaysian Journal of & Volume 6, Issue 1, January 2021 \\
\hline (Mu-ssH) & e-ISSN : 2504-8562 \\
\hline & $\begin{array}{l}\text { Journal home page: } \\
\text { www.msocialsciences.com }\end{array}$ \\
\hline
\end{tabular}

\title{
Amalan Kepimpinan Distributif Guru Besar Terhadap Efikasi Kendiri dalam kalangan Guru Prasekolah
}

\author{
Sinirah Ahmad1, Aida Hanim A. Hamid1 \\ ${ }^{1}$ Fakulti Pendidikan, Universiti Kebangsaan Malaysia (UKM) \\ Correspondence: Sinirah Ahmad (inirahahmad07@gmail.com)
}

\begin{abstract}
Abstrak
Kepimpinan distributif guru besar yang diamalkan di sekolah adalah seiring dengan usaha Kementerian Pendidikan Malaysia (KPM) bagi melaksanakan Pelan Pendidikan Pembangunan (PPPM 2013-2025) dan terkandung dalam bab 5 untuk menyediakan pemimpin sekolah dan guru yang berkesan. Selaras dengan itu, kajian ini bertujuan untuk mengenal pasti tahap amalan kepimpinan distributif guru besar dan tahap efikasi kendiri guru serta hubungan kepimpinan distributif guru besar dengan efikasi kendiri dalam kalangan guru prasekolah daerah Tawau. Kajian ini adalah bersifat kuantitatif yang mengadaptasi dan menyesuaikan soal selidik Distributed Leadership Survey (DLS) dan Teacher's Sense of Efficacy Scale mengikut kontes kajian. Sampel kajian terdiri daripada 80 orang guru-guru prasekolah daerah Tawau, Sabah yang berkhidmat di 48 buah prasekolah. Perisian SPSS versi 26 digunakan untuk menganalisis data kajian dan objektif kajian dapat dicapai melalui kaedah analisis deskriptif dan infrensi (korelasi pearson). Hasil daripada kajian menunjukkan bahawa tahap amalan kepimpinan distributif guru besar berada pada tahap tinggi ( $\min =4.12, \mathrm{SP}=.576)$. Tahap efikasi kendiri dalam kalangan guru prasekolah juga berada pada tahap tinggi $(\min =4.19, \mathrm{SP}=.451)$. Analisis korelasi pearson yang menjelaskan hubungan kepimpinan distributif dengan efikasi kendiri guru prasekolah daerah Tawau pula mencatatkan korelasi yang signifikan $\left(\mathrm{r}=.435^{* *}, \mathrm{p}<.05\right)$ pada tahap sederhana. Dapatan daripada kajian ini menunjukkan bahawa kepimpinan pendidikan masa kini melihat guru besar tidak lagi berperanan sebagai pemimpin tunggal namun telah berarah kepada perkongsian tanggungjawab yang melibatkan guru-guru dalam organisasi sekolah. Amalan kepimpinan distributif guru besar memberikan implikasi terhadap efikasi kendiri guru untuk berubah dengan menyediakan guru dengan program yang dirancang melalui sokongan emosi dan kemahiran untuk mencapai visi, misi dan matlamat bersama.
\end{abstract}

Kata kunci: kepimpinan distributif, guru besar, efikasi kendiri, guru prasekolah

\section{Headteachers Distributive Leadership Practices Towards Self-Efficacy Among Preschool Teachers}

\begin{abstract}
Distributive leadership that is being practiced by headteachers is in Education's (MOE) efforts to enact the National Education Blueprint (NBE 2013-2025), Chapter 5 in particular, which is to prepare effective school leaders and teachers. This research paper thus aimed to determine the level of distributive leadership of headteachers and the level of preschool teacher selfefficacy, alongside the relationship between these two factors among preschool teachers in the Tawau district of Sabah, Malaysia. Quantitative research was conducted by adapting the Distributed
\end{abstract}


Leadership Survey (DLS) and Teacher's Sense of Efficacy Scale according to the local context. Sample size consisted of 80 preschool teachers from the Tawau district, randomly selected from the 48 preschool establishments. SPSS version 26 was used to analyze data and the research objective was achieved through both descriptive analysis and inference (Pearson correlation). Results showed that high levels of distributive leadership among headteachers (mean $=4.12$, SP. $=.451$ ). There was also significant correlation between levels of distributive leadership and self-efficacy of preschool teachers in the Tawau district $\left(\mathrm{r}=.435^{* *}, \mathrm{p}<.05\right)$. Research findings showed that in these current times, headteachers no longer play a singular role in leadership, rather the leadership style has evolved into one of shared responsibility that involves teachers. Distributive leadership practiced by headteachers is implied to be able to change teacher self-efficacy, through programs that provide emotional support and skills to achieve a shared vision, mission and goal.

Keywords: distributive leadership, headteachers, self-efficacy, preschool teacher

\section{Pengenalan}

Kementerian Pendidikan Malaysia (KPM) terus berusaha untuk menyediakan pemimpin sekolah dan guru yang berdedikasi bagi membentuk generasi cemerlang dalam bidang pendidikan yang semakin mencabar. Melalui Pelan Pendidikan Pembangunan Pendidikan Malaysia, 2013 -2025; Bab 5 jelas menunjukkan bahawa dasar pendidikan negara ke arah memastikan semua sekolah mempunyai pemimpin berkualiti tinggi bagi memacu kecemerlangan. Oleh itu, amalan kepimpinan distributif guru besar di sekolah akan menjadi pemangkin kepada matlamat pendidikan negara dalam usaha memantapkan kepimpinan guru besar. Melalui kepimpinan distributif akan membolehkan organisasi mendapat manfaat daripada gabungan kepakaran dan interaksi di antara pemimpin sekolah dan rakan sekerja yang lain, bekerjasama untuk mencapai tujuan bersama sehingga hasilnya lebih berimpak tinggi daripada bekerja secara individu (Gronn, 2000; Spillane, 2005). Kini, pemimpin sekolah yang terdiri daripada guru besar berdepan dengan cabaran mengurus dan mentadbir organisasi sekolah dari seawal peringkat prasekolah lagi. Terdapat bukti yang cenderung menyokong hubungan positif antara kepimpinan distributif dengan peningkatan organisasi. (Harris, 2009; Leithwood dan Mascall, 2008; Harris, 2008).

Dalam pendidikan sekolah rendah, guru besar turut memimpin dan mengurus guru prasekolah agar dapat mengikuti dan mengamalkan semua garis panduan pengurusan prasekolah. Kefahaman dan kerjasama yang diberikan oleh guru besar terhadap guru prasekolah adalah sangat diperlukan dalam usaha guru membentuk psikologi, emosi, kemahiran asas dan sahsiah kanak-kanak. Dengan mengambil kira tahap efikasi kendiri dalam kalangan guru prasekolah, guru besar yang mengamalkan kepimpinan distributif dapat membantu dan memastikan guru prasekolah melaksanakan tugas mendidik kanak-kanak seawal umur 4 sehingga 6 tahun dapat dijalankan dengan sempurna. Sebelum menilai sejauh mana amalan kepimpinan guru besar boleh meningkatkan efikasi kendiri, guru terlebih dahulu perlu menilai efikasi kendiri masing-masing. Ini adalah penting kerana keyakinan seorang guru dapat mengalihkan perubahan sahsiah murid ke arah positif (Bandura, 1997).

\section{Objektif Kajian}

i. Mengenal pasti tahap amalan kepimpinan distributif guru besar.

ii. Mengenal pasti tahap efikasi kendiri dalam kalangan guru prasekolah daerah Tawau.

iii. Menentukan hubungan antara kepimpinan distributif guru besar dengan efikasi kendiri dalam kalangan guru prasekolah daerah Tawau.

\section{Sorotan Literatur}

Pandangan Leithwood dan Riehl (2003) menyarankan bahawa tiga elemen teras dari kepimpinan yang pertama, kepimpinan dianggap sebagai pertalian hubungan antara individu yang memimpin dengan 
mereka yang menyokong usaha kepimpinan yang sedang dilaksanakan untuk mencapai visi, misi dan matlamat yang sama. Kedua ialah, individu yang terlibat dalam membawa pengikutnya untuk mencapai matlamat yang dihajati. Ketiga, kepimpinan adalah fungsi atau tingkah laku seseorang individu dan bukannya kedudukan individu tersebut. Menurut Thompson (2017), elemen asas bagi kepimpinan pendidikan yang berkesan pada abad ke-21 ialah kepemimpinan mesti dikongsi secara meluas dalam organisasi yang sama. Berkongsi kuasa bermaksud bahawa ramai guru yang mempunyai tanggungjawab kepimpinan di sekolah mereka. Isu penglibatan guru sebagai pemimpin ini ditakfrifkan sebagai kepemimpinan bersama, Harris (2008); Leithwood \& Mascall, (2008).

Para sarjana berpendapat bahawa kepimpinan tidak boleh didefinisikan dengan kedudukan formal kepimpinan semata-mata melainkan oleh hasil interaksi pemimpin sekolah, pengikut dan situasi mereka (Spillane, Halverson \& Diamond, 2001). Kerjasama dan pengagihan tugas yang seimbang akan memudahkan guru besar sebagai pemimpin sekolah melaksanakan tanggungjawab dengan lebih terarah dan berkesan. Ini selaras dengan pandangan daripada Rosnarizah \& Zulkifli (2009) yang menyatakan bahawa tanggungjawab di sekolah tidak hanya dipikul oleh pengetua semata-mata tetapi tren ini telah berubah ke arah perkongsian bersama dan penglibatan semua guru dalam memberi dan membuat keputusan bersama. Dengan kata lain, kebersamaan untuk berkongsi dan mengamalkan budaya kerja kepimpinan tidak hanya melibatkan guru besar secara total tetapi juga melibatkan guruguru aliran perdana dan juga guru-guru prasekolah dengan memberi peluang untuk mengambil bahagian dalam merancang dan membuat keputusan. Model Kepimpinan Distributif Gordon (2002) ada empat dimensi iaitu visi, misi dan matlamat, budaya sekolah, amalan kepimpinan dan berkongsi tanggungjawab telah diguna pakai oleh pengkaji. Menurut Gordon (2002), fokus utama kepimpinan distributf ialah perkongsian kuasa antara pemimpin dan pengikut. Apabila tanggungjawab kepimpinan distributf dibahagikan kepada seluruh organisasi, maka penekanan diberikan pada proses kepimpinan dan bukan pada sifat atau gaya seseorang pemimpin.

Konsep efikasi kendiri dianggap sebagai konstruk penting dalam Teori Kognitif Sosial Albert Bandura (1986). Dalam memberi konsep tentang efikasi kendiri, Bandura menerangkan tingkah laku manusia dengan mengambil kira fenomena penyebab timbal balik, iaitu individu dan persekitaran. Efikasi kendiri adalah kemampuan seseorang individu untuk menghadapi sebarang keadaan sama ada susah atau senang dan individu tersebut yakin dan mampu menghadapinya dengan berkesan. Scribner (1989) melihat efikasi kendiri guru dapat dipengaruhi oleh faktor tidak langsung iaitu melalui pemimpin sekolah yang dapat mewujudkan peluang kepada guru untuk belajar menguasai sesuatu kemahiran serta memberi pengalaman baharu. Guru yang mempunyai tahap efikasi kendiri yang rendah akan dapat mengembangkan pandangan dengan lebih luas mengenai situasi dan masalah yang dihadapi dengan mencari jalan penyelesaian alternatif demi mencapai tahap pengajaran yang baik agar pelajar memperoleh kejayaan yang lebih tinggi.

Efikasi kendiri dalam kajian ini merujuk kepada sejauh mana kepercayaan guru terhadap kebolehannya sebagai guru. Juga berkaitan dengan jangkaan guru atau pendidik bahawa dia telah bertingkah laku seperti yang diperlukan untuk menghasilkan atau mencapai sesesuatu tugas tertentu. Dalam kajian ini akan melihat efikasi kendiri dalam kalangan guru prasekolah daerah Tawau dalam menjalankan tugas harian mereka sebagai pendidik di prasekolah Kementerian Pendidikan Malaysia. Oleh itu, kajian ini akan melihat sejauh manakah tahap kepercayaan tentang kemampuan diri guru prasekolah kerana pengkaji melihat ini adalah sangat penting kerana dapat membantu dalam menentukan prestasi profesionalisme guru. Kepercayaan efikasi kendiri guru prasekolah merupakan petunjuk yang signifikan terhadap kepuasan guru dalam mendidik kanak-kanak. Model Efikasi Kendiri Tschannen-Moran \& Hoy (2001) digunakan oleh pengkaji bagi memberi ukuran baharu dalam efikasi kendiri guru. Secara khususnya, penyelidik mengembangkan ukuran efikasi kendiri guru terhadap tugas yang berkaitan dengan pengajaran dalam dimensi penglibatan murid, strategi pengajaran dan pengurusan bilik darjah.

\section{Metod Kajian}

\section{Reka bentuk kajian}


Kajian ini adalah penyelidikan kuantitatif yang menggunakan kaedah tinjauan dengan menjalankan soal selidik bagi mengumpul data dari guru prasekolah mengenai amalan kepimpinan distributif guru besar dan tahap efikasi kendiri guru. Kedah tinjauan menurut Sukamolson (2007) merangkumi penggunaan kaedah persampelan saintifik dengan bentuk soal selidik yang dirancang untuk mengukur ciri-ciri populasi tertentu melalui penggunaan kaedah statistik. Analisis data dilakukan secara deskriptif dan inferensi. Bagi menjelaskan profil responden, analisis kekerapan dan peratusan digunakan. Manakala, untuk menjelaskan tahap amalan kepimpinan distributif guru besar dan tahap efikasi kendiri guru prasekolah, pengkaji menggunakan purata min dan sisihan piawai. Hubungan antara kepimpinan distributif guru besar dan efikasi kendiri guru prasekolah dapat dijelaskan melalui analisis korelasi Pearson.

\section{Populasi dan sampel kajian}

Sasaran populasi adalah pilihan penyelidik dengan memilih subjek kajian secara realistik iaitu dikenali sebagai populasi yang boleh diakses atau penduduk tersedia di dalam komuniti (Gay,Mills \& Airasian, 2012. Dalam kajian ini, populasi sasaran ialah semua guru prasekolah di sekolah rendah daerah Tawau iaitu seramai 100 orang yang terdiri daripada 47 buah prasekolah di sekolah rendah dan sebuah sekolah yang mewakili prasekolah di Institut Pendidikan Guru (IPG) Kampus Tawau. Saiz sampel perwakilan guru prasekolah dalam kajian ini adalah seramai 80 orang dan penentuan saiz sampel ini adalah berdasarkan pengiraan saiz sampel Krejcie dan Morgan (1970).

\section{Instrumen kajian}

Kajian ini menggunakan instrumen Distributed Leadership Survey (DLS) yang diubahsuai dan diadaptasi daripada Davis (2009). Memandangkan perbezaan kontekstual, pengkaji menggunakan 28 item daripada 37 item dari skala ini yang relevan dan diubahsuai mengikut konteks kajian. Bagi mengukur tahap efikasi kendiri guru prasekolah di lokasi kajian, pengkaji menggunakan Instrumen Teacher's Sense of Efficacy Scale yang diadaptasi dan diubahsuai mengikut konteks kajian daripada Tschannen-Moran \& Hoy (2011). Pengkaji menggunakan 20 item soal selidik yang sesuai dengan sampel kajian.

Soal selidik ini terdiri daripada soalan-soalan tertutup beserta ruang jawapan yang akan diedarkan melalui pautan google form yang akan disebarluaskan melalui aplikasi atas talian seperti WhatsApp dan Telegram. Kajian ini menggunakan soal selidik daripada skala Likert 5 point yang dibahagikan kepada 3 bahagian iaitu: Bahagian A ialah demografi responden yang mengandungi 5 item. Manakala, Bahagian B adalah Skala Kepimpinan Distributif Guru Besar (DLS) yang mengandungi soalan tertutup yang terdiri daripada 28 item. Seterusnya di Bahagian C berkaitan Skala Efikasi Kendiri Guru (Teacher's Sense of Efficacy Scale) (TSES) iaitu soal selidik yang akan memberi maklumat tentang tahap efikasi kendiri guru prasekolah yang mengandungi 20 item.

Kesahan dan kebolehpercayaan adalah langkah penting dalam memastikan instrumen yang digunakan dapat mengukur kajian dan menjawab semua persoalan serta mencapai objektif kajian. Item-item dalam soal selidik dirujuk kepada tiga orang pakar bagi mendapatkan pengesahan kandungan soal selidik tersebut. Antara pakar yang telah dikenal pasti iaitu seorang pensyarah Universiti Kebangsaan Malaysia (UKM), seorang pensyarah Institut Pendidikan Guru (IPG) Kampus Tawau, yang mempunyai kelulusan $\mathrm{PhD}$ dalam bidang berkaitan dan seorang guru mata pelajaran sains yang berkhidmat di Sekolah Rendah daerah Tawau dan mempunyai kelulusan PhD dalam bidang pendidikan sains.

\section{Kajian rintis}

Kajian rintis dilaksanakan di 33 buah sekolah rendah yang melibatkan 69 buah kelas prasekolah dalam daerah Lahad Datu. Walau bagaimanapun, kajian ini hanya memerlukan seramai 30 orang guru prasekolah sebagai sampel dalam kajian rintis ini bagi mengetahui dan mengenal pasti kesesuaian dan kesahan soal selidik yang telah dibina. Tujuan kajian rintis adalah untuk melihat kestabilan nilai Cronbach Alpha yang diperoleh melalui kajian rintis (Mohd Faizal \& Wei, 2017). Nilai Cronbach 
Alpha bagi instrumen kajin ini ialah .972 iaitu mencapai nilai cukup tinggi dan sesuai dengan saranan Fraenkel \& Wallen (2005) yang menyatakan bahawa skala dengan nilai pekali alpha 0.7 atau lebih diterima sebagai cukup tinggi. Secara amnya, semakin tinggi Alpha Cronbach maka semakin dipercayai ujiannya

\section{Hasil Kajian}

Responden kajian terdiri daripada 80 orang guru prasekolah daerah Tawau. Berdasarkan jantina, perempuan mencatatkan bilangan yang tertinggi dengan 67 responden (83.7\%) dan lelaki mencatatkan bilangan yang terendah dengan 13 responden (16.3\%). Bagi kategori umur mendapati bahawa 1 responden (1.3\%) berumur 25 tahun ke bawah diikuti dengan 21 responden (26.3\%) berumur 26 hingga 35 tahun, 45 responden (56.3\%) berumur antara 36 hingga 45 tahun dan 13 responden (16.3\%) berumur 46 tahun ke atas. Seterusnya bagi taburan kelayakan akademik mencatatkan bahawa 1 responden (1.3\%) memiliki sijil, 2 responden (2.5\%) memiliki Diploma, 71 responden (88.8\%) memiliki Ijazah Sarjana Muda dan 6 responden (7.5\%) memiliki Ijazah Sarjana (Master). Selain itu, taburan responden berdasarkan pengalaman mengajar mendapati bahawa 12 responden (15\%) telah mengajar antara 1 hingga 5 tahun diikuti dengan 14 responden (17.5\%) adalah antara 6 hingga 10 tahun, 30 responden (37.5\%) adalah antara 11 hingga 15 tahun dan 12 responden (15\%) adalah antara 16 hingga 20 tahun dan 20 tahun ke atas pengalaman mengajar. Berdasarkan lokasi mengajar didapati bahawa majoriti responden mengajar di bandar dengan jumlah 41 responden $(51.3 \%)$ dan diikuti dengan luar bandar dengan 30 responden (37.5\%). Manakala minoriti responden adalah mengajar di pendalaman dengan jumlah 9 responden $(11.3 \%)$.

\section{Tahap Kepimpinan DistributifGuru Besar}

Melalui analisis deskriptif yang telah dijalankan mendapati bahawa kepimpinan distributif terdiri daripada 4 dimensi kepimpinan iaitu visi, misi dan matlamat, budaya sekolah, amalan kepimpinan dan berkongsi tanggungjawab berada pada tahap tinggi. Analisis deskriptif skor min tahap amalan kepimpinan deskriptif guru besar diterangkan melalui Jadual 1.

Jadual 1 : Tahap Kepimpinan Distributif Guru Besar

\begin{tabular}{lcc}
\hline Dimensi & Min & Tahap \\
\hline Amalan Kepimpinan Distributif & $\mathbf{4 . 1 2}$ & Tinggi \\
Visi, Misi dan Matlamat & 4.22 & Tinggi \\
Budaya Sekolah & 4.12 & Tinggi \\
Amalan Kepimpinan & 4.02 & Tinggi \\
Tanggungjawab Bersama & 4.11 & Tinggi \\
\hline
\end{tabular}

Jadual 2 menunjukkan bahawa dimensi bagi visi, misi dan matlamat mencatatkan min 4.22 (tinggi), budaya sekolah mencatatkan min 4.12 (tinggi), amalan kepimpinan adalah 4.02 (tinggi) dan tanggungjawab bersama adalah 4.11 (tinggi). Bagi keempat-empat dimensi ini visi, misi dan matlamat mencatatkan min yang tertinggi dan amalan kepimpinan mencatatkan min yang terendah. Seterusnya bagi keseluruhan amalan kepimpinan distributif mencatatkan min 4.12 iaitu berada pada tahap yang tinggi.

Jadual 2 : Skor Min Tahap Kepimpinan Distributif Guru Besar Tiap Dimensi

\begin{tabular}{lccc}
\hline Pernyataan & min & $\begin{array}{c}\text { Sisihan } \\
\text { piawai }\end{array}$ & Tahap \\
\hline $\begin{array}{l}\text { Dimensi Visi, misi dan matlamat } \\
\text { Guru besar saya mempunyai visi sekolah yang ditulis dengan }\end{array}$ & 4.35 & .553 & Tinggi \\
$\begin{array}{l}\text { jelas } \\
\text { Guru besar saya mempunyai misi sekolah yang ditulis dengan } \\
\text { jelas }\end{array}$ & 4.36 & .556 & Tinggi \\
\hline
\end{tabular}




Guru besar saya mempunyai matlamat sekolah yang ditulis
dengan jelas
Guru besar saya dapat mencapai visi sekolah
Guru besar saya dapat mencapai misi sekolah
Guru besar saya dapat mencapai matlamat sekolah
Guru besar saya wujudkan kebersamaan dalam mencapai visi
sekolah
Guru besar saya wujudkan kebersamaan dalam mencapai misi
sekolah
Guru besar saya wujudkan kebersamaan dalam mencapai
matlamat sekolah

$\begin{array}{lll}4.26 & .589 & \text { Tinggi } \\ 4.12 & .643 & \text { Tinggi } \\ 4.15 & .618 & \text { Tinggi } \\ 4.16 & .538 & \text { Tinggi } \\ 4.20 & .560 & \text { Tinggi } \\ 4.21 & .588 & \text { Tinggi } \\ 4.22 & .573 & \text { Tinggi }\end{array}$

\section{Dimensi Budaya Sekolah}

Guru besar saya paling berpengaruh mencipta budaya sekolah Guru besar saya wujudkan budaya saling mempercayai dalam kalangan kakitangan sekolah

Guru besar saya wujudkan perubahan dalam budaya kerja sekolah.

Guru besar saya berpengetahuan dalam menyelesaikan masalah di prasekolah.

Guru besar saya menggalakkan guru prasekolah mengambil peranan kepimpinan sekolah.

Guru besar saya menggalakkan penyertaan aktif guru prasekolah semasa mesyuarat guru.

Guru besar saya dapat mewujudkan budaya harmoni antara guru, ibu bapa dan komuniti.

$\begin{array}{lll}4.12 & .663 & \text { Tinggi } \\ 4.11 & .573 & \text { Tinggi } \\ 4.12 & .581 & \text { Tinggi } \\ 3.98 & .684 & \text { Tinggi } \\ 4.12 & .520 & \text { Tinggi } \\ 4.21 & .520 & \text { Tinggi } \\ 4.16 & .583 & \text { Tinggi }\end{array}$

\section{Dimensi Amalan Kepimpinan}

Guru besar saya menyediakan peluang latihan pembangunan profesionalisme dalam kepimpinan.

Guru besar saya memberi motivasi untuk menjadi pemimpin. Guru besar saya memberi peluang untuk membuat keputusan. Guru besar saya menggalakkan peningkatan tahap pencapaian akademik.

Guru besar saya menyediakan infrastruktur yang mencukupi untuk melaksanakan pengajaran dan pembelajaran di prasekolah.

Guru besar saya berpengetahuan luas dalam pengajaran dan pembelajaran prasekolah.

$\begin{array}{lll}3.93 & .400 & \text { Tinggi } \\ 4.16 & .514 & \text { Tinggi } \\ 4.12 & .487 & \text { Tinggi } \\ 4.12 & .487 & \text { Tinggi } \\ 3.97 & .573 & \text { Tinggi } \\ & & \\ 3.85 & .695 & \text { Tinggi }\end{array}$

\section{Dimensi Berkongsi Tanggungjawab}

Guru besar saya berbincang tentang perkembangan sahsiah murid.

Guru besar saya menggalakkan perkongsian bahan pengajaran,

Guru besar saya membantu dalam pengurusan prasekolah.

Guru besar saya sentiasa berbincang menyelesaikan masalah di prasekolah.

Guru besar saya memberi maklum balas untuk memperbaiki pengurusan prasekolah.

Guru besar saya menggalakkan perkongsian idea untuk kecemerlangan prasekolah.

\begin{tabular}{lll}
4.07 & .590 & Tinggi \\
4.10 & .492 & Tinggi \\
4.10 & .667 & Tinggi \\
4.13 & .651 & Tinggi \\
4.12 & .643 & Tinggi \\
4.16 & .604 & Tinggi \\
$\mathbf{4 . 1 2}$ & $\mathbf{. 5 7 6}$ & Tinggi \\
\hline
\end{tabular}

Purata

$4.12 \quad .576$ 


\section{Tahap efikasi kendiri dalam kalangan guru prasekolah}

Efikasi kendiri terdiri daripada 3 dimensi. Efikasi kendiri ini terdiri daripada penglibatan murid, strategi pengajaran dan pengurusan bilik darjah. Setiap dimensi ini telah dikenal pasti dan diperincikan bagi menentukan tahap efikasi kendiri dalam kalangan guru. Analisis data mengenai tahap efikasi kendiri dalam kalangan guru prasekolah daerah Tawau secara keseluruhannya yang melibatkan 3 dimensi dijelaskan dalam Jadual 3 di bawah

Jadual 3: Tahap Efikasi Kendiri Dalam Kalangan Guru Prasekolah

\begin{tabular}{lcc}
\hline Dimensi & Min & Tahap \\
\hline Efikasi Kendiri Guru & $\mathbf{4 . 1 9}$ & Tinggi \\
Penglibatan Murid & 4.21 & Tinggi \\
Strategi Pengajaran & 4.20 & Tinggi \\
Pengurusan Bilik Darjah & 4.14 & Tinggi \\
\hline
\end{tabular}

Perincian tahap efikasi kendiri guru mengikut tiap dimensi diterangkan melalui Jadual 4

Jadual 4: Skor Min Tahap Efikasi Kendiri Dalam Kalangan Guru Prasekolah

\begin{tabular}{|c|c|c|c|}
\hline Pernyataan & $\min$ & $\begin{array}{l}\text { Sisihan } \\
\text { piawai }\end{array}$ & Tahap \\
\hline \multicolumn{4}{|l|}{ Dimensi Penglibatan Murid } \\
\hline Saya boleh menarik minat murid untuk mengikuti pembelajaran & 4.26 & .470 & Tinggi \\
\hline Saya boleh memupuk kreativiti murid & 4.22 & .420 & Tinggi \\
\hline Saya boleh membantu murid berfikir secara kritis & 4.16 & .462 & Tinggi \\
\hline $\begin{array}{l}\text { Saya boleh memberi motivasi kepada murid agar dapat menyiapkan } \\
\text { tugasan sekolah }\end{array}$ & 4.31 & .492 & Tinggi \\
\hline $\begin{array}{l}\text { Saya boleh memastikan murid yakin dengan kebolehan } \\
\text { menyiapkan tugasan sekolah }\end{array}$ & 4.25 & .463 & Tinggi \\
\hline Saya boleh membuat intervensi awal untuk membantu murid & 4.16 & .403 & Tinggi \\
\hline $\begin{array}{l}\text { Saya boleh membuat tindakan susulan mengikut perkembangan } \\
\text { murid }\end{array}$ & 4.16 & .403 & Tinggi \\
\hline \multicolumn{4}{|l|}{ Dimensi Strategi Pengajaran } \\
\hline $\begin{array}{l}\text { Saya boleh memberi jawapan kepada soalan yang sukar } \\
\text { daripada murid }\end{array}$ & 4.16 & .434 & Tinggi \\
\hline Saya boleh menetapkan objektif pembelajaran dengan baik & 4.26 & .442 & Tinggi \\
\hline Saya boleh mewujudkan suasana belajar sambil bermain & 4.27 & .449 & Tinggi \\
\hline $\begin{array}{l}\text { Saya boleh mempelbagaikan strategi pengajaran mengikut } \\
\text { tahap kebolehan murid }\end{array}$ & 4.27 & .449 & Tinggi \\
\hline Saya boleh gunakan kepelbagaian dalam strategi pentaksiran murid & 4.12 & .420 & Tinggi \\
\hline Saya boleh menggunakan strategi pengajaran alternatif di dalam kelas & 4.12 & .368 & Tinggi \\
\hline Saya boleh berikan penjelasan apabila murid keliru & 4.25 & .463 & Tinggi \\
\hline \multicolumn{4}{|l|}{ Dimensi Pengurusan Kelas } \\
\hline Saya boleh meramal tingkah laku murid & 4.10 & .518 & Tinggi \\
\hline $\begin{array}{l}\text { Saya boleh mengawal tingkah laku murid yang mengganggu dalam } \\
\text { kelas }\end{array}$ & 4.16 & .462 & Tinggi \\
\hline Saya boleh mengawal murid yang membuat bising & 4.20 & .461 & Tinggi \\
\hline Saya boleh menjalankan aktiviti mengikut jadual & 4.03 & .538 & Tinggi \\
\hline $\begin{array}{l}\text { Saya boleh mewujudkan pengurusan bilik darjah dalam setiap } \\
\text { kumpulan murid }\end{array}$ & 4.16 & .403 & Tinggi \\
\hline Saya boleh memastikan setiap murid mengikuti peraturan bilik darjah & 4.20 & .461 & Tinggi \\
\hline Purata & 4.19 & .4517 & Tinggi \\
\hline
\end{tabular}




\section{Hubungan Kepimpinan Distributifguru besar dengan tahap efikasi}

Jadual 5 menunjukkan hubungan antara kepimpinan distributif dengan efikasi guru. Hasil dapatan menjelaskan bahawa terdapat hubungan yang signifikan antara kepimpinan distributif dengan tahap efikasi kendiri guru prasekolah $\left(\mathrm{r}=-0.435^{* *}, \mathrm{p}=<.05\right)$ dengan tahap hubungan sederhana.

Jadual 5 : Hubungan Kepimpinan Distributif Guru Besar dengan

Efikasi Kendiri Guru Prasekolah

\begin{tabular}{lll}
\hline & & Efikasi Kendiri \\
Kepimpinan Distributif & Pearson Correlation & $.435^{* *}$ \\
& Sig. (2-tailed) & 0.000 \\
& $\mathrm{~N}$ & 80 \\
\hline
\end{tabular}

** korelasi signifikan pada tahap $\alpha=0.05$

Analisis korelasi menunjukkan bahawa hubungan adalah signifikan pada tahap sederhana dengan nilai tertinggi adalah dimensi strategi pengajaran $(\mathrm{r}=-0.435, \mathrm{p}=0.000)$ dan nilai korelasi terendah ialah dimensi pengurusan bilik darjah $(r=0.305, p=0.000)$. Ini bermakna semakin meningkat persepsi guru prasekolah terhadap kepimpinan distributif guru besar maka efikasi kendiri guru akan turut meningkat. Oleh yang demikian, dapatlah dirumuskan bahawa hipotesis null bagi kajian ini iaitu tidak terdapat hubungan signifikan antara amalan kepimpinan distributif guru besar dengan efikasi kendiri dalam kalangan guru prasekolah daerah Tawau adalah hipotesis null ditolak.

Jadual 6: Perincian kekuatan hubungan kepimpinan distributif guru besar dengan dimensi efikasi kendiri guru

\begin{tabular}{llll}
\hline $\begin{array}{l}\text { Dimensi Efikasi Kendiri } \\
\text { Guru }\end{array}$ & Korelasi Pearson & Sig. (2-tailed) & Kekuatan hubungan \\
\hline Penglibatan Murid & $.435^{* *}$ & 0.000 & Sederhana \\
Strategi Pengajaran & $.447^{* *}$ & 0.000 & Sederhana \\
Pengurusan Bilik Darjah & $.305^{* *}$ & 0.000 & sederhana \\
\hline
\end{tabular}

Jadual 7 : Interpretasi hubungan pekali (r)

\begin{tabular}{ll}
\hline Pekali (r) & Hubungan \\
\hline .00 hingga .20 & Tidak ada atau sedikit, jika ada korelasi \\
.20 hingga .40 & Korelasi lemah \\
.40 hingga .60 & Korelasi sederhana \\
.60 hingga .80 & Korelasi kuat \\
.80 hingga 1.00 & Korelasi sangat tinggi atau sempurna \\
\hline
\end{tabular}

Sumber : Adaptasi daripada Hatcher, 2003

\section{Perbincangan Kajian}

\section{Persepsi Terhadap Kepimpinan Distributif}

Bagi memastikan sesebuah organisasi berdaya maju, visi, misi dan matlamat hendaklah ditetapkan bagi memberi maklumat kepada warga sekolah agar jelas akan nilai-nilai pendidikan yang diketengahkan untuk menyokong hala tuju pendidikan negara (Gordon, 2005). Ia bertepatan dengan dapatan kajian iaitu majoriti responden menyatakan bahawa guru besar dapat mencapai visi, misi dan matlamat sekolah.

Kepentingan kepimpinan distributif dalam mengukuhkan kualiti persekitaran sekolah turut dibincangkan oleh sarjana seperti Oduro (2014), Leithwood, Louis, Anderson \& Walstrom (2016). Kocolowski (2010) turut menyatakan bahawa kepimpinan distributif yang melibatkan interaksi sosial 
bersama ahli organisasi membawa kepada perkongsian tanggungjawab dan kesatuan. Ia dapat dilihat dengan jelas apabila responden membuktikan bahawa guru besar menggalakkan guru prasekolah mengambil peranan dalam kepimpinan sekolah. Ia bertujuan untuk memberi peluang setiap guru untuk turut mengambil peranan dalam kepimpinan. Selain itu, guru besar turut menggalakkan penyertaan aktif guru prasekolah semasa mesyuarat guru. Secara tidak langsung, guru-guru boleh melontarkan idea dan diberikan peluang untuk membuat keputusan bagi penambahbaikan pendidikan prasekolah.

Perkongsian kepimpinan melibatkan guru besar dan guru adalah konsep yang sering dibincangkan dalam kepimpinan pendidikan. Dalam mengamalkan kepimpinan distributif, guru-guru dapat meningkatkan kecemerlangan murid-murid dengan menggerakkan perubahan kepimpinan ke arah kepimpinan tersebar (Webb, 2015). Dapatan kajian daripada Zuraidah \& Mohd Izham (2018) menunjukkan bahawa tahap kepimpinan distributif pengetua di daerah Putrajaya mengikut persepsi guru menunjukkan tahap visi, misi dan matlamat, budaya sekolah, perkongsian tanggungjawab dan amalan kepimpinan dalam kajian ini adalah baik. Dapatan ini seterusnya akan dapat mewujudkan iklim persekitaran sekolah yang kondusif dan selamat kepada guru-guru untuk meningkatkan efikasi kendiri yang tinggi dalam menjalankan tugas, peranan dan tanggungjawab mereka Secara tidak langsung, hubungan erat sesama ahli organisasi dapat dibentuk

\section{Tahap Efikasi Kendiri Guru Prasekolah}

Demi memastikan matlamat sistem pendidikan dapat dicapai, guru bertindak sebagai individu yang bertanggungjawab untuk menyampaikan ilmu menerusi proses pembelajaran dan pengajaran untuk mencapai visi dan misi pendidikan negara. Dapatan kajian menyatakan bahawa guru boleh membuat intervensi awal untuk membantu murid sebagai contoh membuat sesi terapi bagi mengenal pasti potensi diri murid. Seterusnya, guru juga boleh membuat tindakan susulan mengikut perkembangan murid. Secara tidak langsung, matlamat dapat dicapai dengan adanya efikasi kendiri yang positif dalam kalangan guru.

Dalam konteks ini, strategi pengajaran yang diaplikasikan oleh guru mestilah bersesuaian dengan prestasi murid. Seperti yang jelas dinyatakan dalam dapatan kajian, majoriti responden menyatakan bahawa mereka menggunakan strategi pengajaran alternatif di dalam kelas. Tinjauan (Ross, 1998) mengenai kesan efikasi kendiri guru menyimpulkan bahawa, keberkesanan guru yang lebih tinggi secara konsisten dikaitkan dengan penggunaan teknik pengajaran yang lebih mencabar dan sukar, dengan kesediaan guru untuk melaksanakan program inovatif, dan mengamalkan amalan pengurusan bilik darjah yang dapat mempromosikan tanggungjawab secara menyeluruh kepada murid.

Sebagai seorang guru, kemahiran menguruskan bilik darjah merupakan satu aspek yang penting. Ia dikaitkan dengan kesediaan guru untuk mengajar serta menyediakan persekitaran belajar yang selesa. Merujuk kepada dapatan kajian, majoriti responden menyatakan bahawa mereka dapat mewujudkan pengurusan bilik darjah dalam setiap kumpulan murid. Selain itu, responden turut berupaya untuk mengawal tingkah laku murid yang mengganggu dalam kelas. Situasi ini jelas menunjukkan bahawa responden mempunyai kemahiran pengurusan bilik darjah yang baik.

\section{Hubungan Kepimpinan Distributif Guru Besar Terhadap Efikasi Kendiri Guru Prasekolah}

Dapatan daripada kajian ini menunjukkan hubungan kepimpinan distributif guru besar dan tahap efikasi kendiri guru prasekolah adalah signifikan dengan tahap kekuatan adalah sederhana $(\mathrm{r}=.435)$ Dapatan kajian ini adalah selari dengan dapatan kajian oleh Hasanvand, Zeinabadi, Shomami \& Karfestani (2013) melalui kajian hubungan kepimpinan pengetua terhadap efikasi kendiri guru di sekolah menengah. Kajian mendapati bahawa terdapat pekali korelasi antara kepimpinan distributif pengetua dengan kesedaran efikasi kendiri guru iaitu $(\mathrm{R}=0.343)$ pada tahap 0.05 adalah signifikan walaupun pada tahap lemah. Selain daripada itu, kajian ini seiring dengan dapatan oleh pengkaji De Marco (2018) yang menunjukkan analisis korelasi terdapat hubungan statistik yang signifikan antara kedua pemboleh ubah iaitu kepimpinan distributif dengan efikasi kendiri guru. Korelasi antara soal selidik dalam Distributed Leadership Inventory (DLI) dan Teacher Self Efficacy Scale (TSES) adalah 
.405 ( $\mathrm{r}=.405, \mathrm{~N}=162, \mathrm{p}=.000$ ). Begitu juga dengan kajian Ronarizah \& Hussein (2016) yang menunjukkan korelasi positif yang signifikan namun berbeza sedikit dari segi tahap kekuatan hubungan yang menunjukkan tahap tinggi $(r=.50)$ di Sekolah Berasrama Penuh dan Sekolah Menengah Kebangsaan di Malaysia.

\section{Implikasi Kajian}

Implikasi daripada hasil kajian ini dibincangkan bagi meningkatkan lagi keberkesanan kepemimpinan guru besar serta efikasi kendiri guru prasekolah daerah Tawau. Menurut Bass dan Avolio (2010), kepimpinan guru besar adalah suatu kemahiran yang boleh dipelajari. Kajian ini juga turut memberikan sumbangan yang penting kepada kepimpinan guru besar supaya dapat memimpin organisasi dengan lebih progresif dan produktif. Oleh itu dicadangkan guru besar diberi peluang mengikuti latihan kemahiran kepimpinan supaya amalan kepimpinan yang akan digunakan di sekolah adalah bersesuaian dengan situasi dan tempat demi menjaga keseimbangan kepimpinan dalam organisasi. Perkara ini penting kerana ia dapat meningkatkan komitmen kerja serta motivasi guru di sekolah. Bagi menjamin kualiti pengajaran dan pembelajaran di bilik darjah prasekolah dan mengawal tingkah laku kanak-kanak dalam kelas, efikasi kendiri guru prasekolah yang berkaitan dengan kompetensi emosi dan kemahiran perlu dipertingkatkan. Latihan berterusan atau berkala akan dapat mengasah kemahiran sedia ada agar guru prasekolah lebih bersedia berhadapan dengan cabaran dunia pendidikan pada masa hadapan dan seterusnya dapat mencapai misi, visi dan matlamat pendidikan negara.

\section{Kesimpulan}

Guru dan pentadbir di sekolah mempunyai peranan dan fungsi yang sama penting dalam kemenjadian sesebuah organisasi. Persepsi guru prasekolah daerah Tawau terhadap gaya kepimpinan distributif guru besar dan tahap efikasi kendiri guru prasekolah dilihat pada tahap tinggi. Selain daripada itu, hubungan yang signifikan dengan kekuatan sederhana terhadap kepimpinan distributd dengan efikasi kendiri guru telah dapat dibuktikan. Begitulah hasil dapatan dalam kajian ini dan beberapa kajian lepas. Dalam aspek psikologi, guru merupakan manusia biasa yang boleh dipengaruhi atau tidak oleh sesuatu faktor dalaman dan persekitaran yang membentuk efikasi kendiri. Guru besar yang mengamalkan kepimpinan distributif juga boleh mempengaruhi ataupun tidak efikasi kendiri seseorang guru. Oleh itu, kajian ini adalah bersesuaian untuk dilanjutkan kepada beberapa kajian akan datang yang akan memfokuskan kepada aspek lain yang ingin diketahui dapatan kajiannya. Diharapkan semua guru prasekolah akan terus dapat meningkatkan efikasi kendiri walau apa juga gaya kepimpinan yang diamalkan oleh guru besar demi membina sahsiah dan modal insan dari awal persekolahan lagi.

\section{Rujukan}

Avolio, B., Bass, B.M. \& Jung D.I. (2010). Re-examining the components of transformational and transactional leadership using the Multifactor Leadership. Journal of Occupational and Organizational Psychology, 72(4), 441-462

Bandura, A. (1986). Social foundation of thought and action: A social cognitive theory. Englewood Cliffs, NJ: Prentice-Hall.

Bandura, A. (1997) Self-efficacy: The exercise of control. New York: W.H. Freeman.

Creswell, J. (2003). Research design: Qualitative, quantitative and mixed methods approach (2nd ed.).

Gay, L.R., Mills, G.E., \& Airasian, P. (2012). Education Research Competencies for Analysis and Applications. Tenth Edition. Pearson Education, Inc.

Gordon Z V. (2005). The effect of distributed leadership on student achievement. PhD Dissertation. New Britain. Central Connecticut State University.

Gronn, P. (2000) Distributed properties: A new architecture for leadership. Educational.

Harris, A. (2008). Distributed Leadership: Developing Tomorrow's Leaders. Routledge, London.

Harris, A. (2009). Distributed Leadership: Different Perspectives, Springer, Amsterdam. 
Hasanvand, M.M., Zeinabadi, H.R., Shomami, M.A. \& Karfestani, Z.J. (2013). The Study of Relationship Between Distributed Leadership and Academic Optimism in High Schools of Iran. Australian Journal of Basic and Applied Sciences, 7(7): 623-630.

Hatcher, L. (2003). Step by Step Basic Statistics Using SAS. Cary, NC: SAS Institute Inc.

Kementerian Pendidikan Malaysia. (2013). Pelan Pembangunan Pendidikan Malaysia 2013-2015. Putrajaya: Kementerian Pendidikan Malaysia.

Kocolowski, M.D. (2010). Shared Leadership: Is It Time for a Change? Emerging Leadership Journeys 3(1): 22-32.

Krejcie, R.V \& Morgan, D.W. (1970). Determining Sample Size for Research Activities. Educational And Psychological Measurement. 1970, 30, 607-610.

Leithwood, K.A., \& Riehl, C., (2003). What we know about successful school leadership. Philadelphia, PA: Laboratory for Student Success, Temple University.

Leithwood, K. Mascall, B., Straus, T., \& Sacks, R. (2008). The relationship between distributed leadership and teachers' academic optimism. Journal of Educational Administration, 46(2), 214 228.

Leithwood, K., Louis, K. S., Anderson, S., \& Walstrom, K. (2016). How leadership influences student learning. New York: The Wallace Foundation,

Mohd Faizal Nizam Lee Abdullah \& Wei. L.T. (2017). Kesahan dan Kebolehpercayaan Instrumen Penilaian Kendiri Pembelajaran Geometri Tingkatan Satu. Malaysian Journal of Learning and Instruction, 14(1); 211-265.

Oduro, G. K. T. (2014). Distributed leadership in schools: What English teacher say about the 'pull'and 'push' factors. Paper presented at the British Educational Research Association Annual Conference University of Manchester.

Rosnarizah Abdul Halim \& Zulkifli Abdul Manaf. (2009). Kajian Eksplorasi Distributed Leadership di Malaysia. Kertas Penyelidikan Prosiding Seminar Nasional Pngurusan dan Kepimpinan Pendidikan ke-16. Institut Aminuddin Baki, Genting Highlands.

Rosnarizah Abdul Halim \& Hussein Ahmad. (2016). Distributed leadership, contextual factor and teachers' self-efficacy in Malaysia. Malaysian Online Journal of Educational Management (MOJEM), 3(3), 1-12.

Ross, J.A. (1998). The antecedents and consequences of teacher efficacy, in Brophy, J. (Ed.), Advances in Research in Teaching, 7, 49-73.

Spillane, J. P., Halverson, R., \& Diamond, J. B. (2001). Investigating school leadership practice: A distributed perspective. Educational Researcher, 30(3), 23-28.

Spillane, J. P. (2005). Distributed leadership. The Educational Forum, 69, 143-150.

Tschannen-Moran, M., Hoy, A. W. (2001). Teacher efficacy: capturing an elusive construct. Teaching and Teacher Education, 17, 783-805.

Thompson, C.S. (2017). Teachers' Expectation of Educational Leaders' Leadership Approach and Perspectives on the Principalship: Identifying Critical Leadership Paradigms for the 21 st Century, Journal of Organizational \& Educational Leardership, 2(2).

Webb, R. (2015). Learning teaching and learning in the primary school. Educational Management Administration \& Leadership, 33(1), 69-91.

Zuraidah Muda \& Mohd Izham Mohd Hamzah. (2018). Amalan Kepimpinan Distributif Hubungannya Modal Psikologi di Sekolah Menengah Daerah Putrajaya. Research Gate: Conference paper. 